\title{
Isolation and Characterization of Probiotic Lactobacillus spp. from Fermented Food Sources
}

\author{
Shilpa Sabnis and Neha Pawar* \\ Department of Microbiology, the Institute of Science, Mumbai-400 032, India \\ *Corresponding author
}

\begin{abstract}
A B S T R A C T

\begin{tabular}{|l|}
\hline Ke y w o r d s \\
Probiotic bacteria, \\
Lactobacilli, Bile \\
tolerance, Acid \\
tolerance, \\
Antibiotic \\
sensitivity, \\
Antibacterial. \\
\hline Article Info \\
\hline Accepted: \\
26 August 2017 \\
Available Online: \\
10 September 2017 \\
\hline
\end{tabular}

Probiotic bacteria can be used as a therapeutic strategy to ameliorate human diseases. This has led to the increase in the use of probiotics as functional foods. Lactic acid bacteria are one of the major strains to be used as probiotics. Therefore, the present study was aimed at isolating, identifying and characterizing lactobacilli from fermented food sources viz. curd and idli batter in terms of their suitability as probiotics as well as antibiotic sensitivity. Both the isolated lactobacilli viz. LAB C (from curd) and LAB IB (from idli batter) were found to show tolerance to bile salts (upto $1.5 \%$ ) and could tolerate acidic conditions (low $\mathrm{pH}$ values of $\mathrm{pH} 3$ ) for upto $3 \mathrm{~h}$. On performing antibiotic susceptibility test using Disc Diffusion Method, both LAB C and LAB IB showed low level resistance resistance to all antibiotics used in the study viz. Nalidixic acid, Nitrofurantoin, Cephalothin, Ampicilin, Co-trimaxazole except Norfloxacin. On the other hand they themselves were found to demonstrate a broad spectrum activity towards the pathogens viz. Escherichia coli, Staphylococcus aureus, Klebsiella pneumoniae, Proteus, Candida albicans, Salmonella paratyphi $B$ used in the study thus suggesting the possibility of their use as live biotherapeutic probiotic agents.
\end{abstract}

\section{Introduction}

Over recent decades, the development and consumption of functional probiotic foods has been increasing alongside awareness of their beneficial effects in promoting gut health as well as in disease prevention and therapy, and this has raised interest in health-promoting foods. Major probiotic mechanisms of action include enhancement of the epithelial barrier, increased adhesion to intestinal mucosa, and concomitant inhibition of pathogen adhesion, competitive exclusion of pathogenic microorganisms, production of anti-bacterial substances and modulation of the immune system (Bermudez-Brito et al., 2012). Probiotic microorganisms can shape the immune system both at the local and systemic level, which will allow future probiotics as treatments for many diseases.

Recent scientific work on the properties and functionality of living micro-organisms in food have suggested that probiotics play an important role in immunological, digestive and respiratory functions, and that they could have a significant effect on the alleviation of infectious diseases in children and other highrisk groups (Gogineni et al., 2013).

To colonize the gastrointestinal tract, probiotic strains need to be ingested as large 
populations and on a daily basis. Therefore, food manufacturers are trying to include probiotic strains in foods and beverages which are part of a normal diet to provide health defense while enjoying meals and to differentiate such functional products from concentrated probiotic preparations available as capsules, powders, or liquids (BermudezBrito et al., 2012).

Most probiotic-containing food products use lactic acid bacteria that have a long history of safe use in foods. As long as the strain is devoid of any transferable antibiotic resistance genes, members of the genera Lactococcus, Lactobacillus, and Bifidobacterium are considered safe; infections in humans by these genera are extremely rare (Sanders et al., 2007). Probiotic lactic acid bacteria are often found naturally in foodstuffs such as milk, meat and vegetables (Setyawardani et al., 2011).

Therefore, in the present study, an attempt was made to isolate and identify probiotic lactobacilli from milk derived products as well as fermented foodstuffs like idli batter and curd.

\section{Materials and Methods}

\section{Isolation and identification of lactic acid bacteria}

The lactobacilli from curd and idli batter were isolated sterile de Man Rogossa and Sharpe (MRS medium) anaerobically at $37^{\circ} \mathrm{C} / 48 \mathrm{~h}$.

The isolates were identified on the basis of their colonial, morphological and biochemical characteristics using standard microbiological techniques on comparison with Bergey's Manual of Determinative Microbiology. Their identity was confirmed using Biomérieux Vitek 2 Compact SYSTEM. The isolates were maintained at $4^{0} \mathrm{C}$.

\section{Characterization of probiotic properties of Lactobacillus isolates}

\section{Determination of their resistance to low $\mathrm{pH}$}

Isolated cells were harvested from MRS broth by centrifugation $\left(2000 \mathrm{rpm} / 10 \mathrm{~min}\right.$ at $\left.4{ }^{\circ} \mathrm{C}\right)$. The pellet was washed with sterile Phosphate Buffered Saline ( $\mathrm{pH}$ 7.2) and the cells were re-suspended in sterile PBS ( $\mathrm{pH} 3$ ).

Tubes were incubated at $37^{\circ} \mathrm{C}$. Aliquots were taken after $0,1,2$, and $3 \mathrm{~h}$ respectively and inoculated in sterile MRS broth followed by incubation at $37^{\circ} \mathrm{C}$ anaerobically for $48 \mathrm{~h}$. Results were estimated in terms of its turbidity ensuring its growth which was further confirmed spectrophotometrically.

\section{Determination of their resistance to bile salt}

Overnight cultures of the isolates were independently inoculated into sterile MRS broth containing $0.3 \%$ and $1.5 \%$ of bile salt respectively. After $2 \mathrm{~h}$, a viable count was carried out and plates were incubated at $37^{\circ} \mathrm{C}$ for 48h anaerobically (Gotcheva et al., 2002).

Determination of their resistance to antibiotics using disc diffusion method (Bauer et al., 1966)

Overnight culture of the isolates was seeded into sterile MRS Agar. Hexadiscs containing various antibiotics viz. Nalidixic acid (NA), Nitrofurantoin (NIT), Cephalothin (CEP), Ampicilin (AMP), Co-trimoxazole (COT), Norfloxacin (NX) were placed on this seeded MRS agar and the plates were incubated at $37^{\circ} \mathrm{C}$ anaerobically for $24 \mathrm{~h}$.

The sensitivity of the isolates to various antibiotics was recorded in terms of the zones of inhibition obtained around the antibiotic discs (Hummel et al., 2007). 
Determination of their antimicrobial activity on bacterial pathogens using agar cup method

The antimicrobial activity of the cell free supernatant (CFS) obtained from MRS broth containing $\mathrm{LAB}$ incubated at $37^{\circ} \mathrm{C} / 48 \mathrm{~h}$ followed by centrifugation at $5000 \mathrm{rpm}$ /15min was checked using Agar Cup Method. Eighteen hour old cultures of bacterial pathogens (viz. Escherichia coli, Staphylococcus aureus, Klebsiella pneumoniae,, Proteus, Candida albicans, Salmonella paratyphi $B$ (Culture density $10^{8}$ cells/ ml) were individually seeded into sterile Nutrient Agar. Wells $(0.6 \mathrm{~mm})$ were bored with help of cork borer to which the CFS was added. Plates were incubated at $37^{\circ} \mathrm{C}$ for $24 \mathrm{~h}$. The sensitivity of the isolates was recorded in terms of the zones of inhibition obtained around the wells.

\section{Results and Discussion}

\section{Identification of isolates}

Presumptive identification of the isolates was carried out on the basis of biochemical tests after comparing with Bergey's manual and with the help of Biomérieux Vitek 2 Compact SYSTEM, with anaerobic cards which is basically an automated microbiology system utilizing growth-based technology. All the isolates from idli batter and curd were found to be catalase negative, non-spore forming, non-motile, Gram positive and oxidase negative bacilli fermenting sugars without gas formation. The isolates were identified to belong to Lactobacillus spp.

\section{Characterization of probiotic properties of Lactobacillus isolates}

\section{Determination of their resistance to low pH}

Being able to tolerate acidic stress is one of the major selection criteria for probiotic strains. The probiotic bacteria are normally subjected to unfavorable physiological conditions viz. acidic environment and bile secretions of the Gastrointestinal (GI) tract. Viability of these bacteria upon ingestion and sufficient survival through the transit to GI tract is crucial for conferring any health benefits to the host. Survival at $\mathrm{pH} 3$ is a significant feature, as ingestion with food lowers the $\mathrm{pH}$ in the stomach to 3 or even lesser (Kumar et al., 2015). In the present study, the isolates were tested for their survival at $\mathrm{pH} 3.0$ for $1,2,3$ and $4 \mathrm{~h}$. respectively. Both the Lactobacillus isolates were found to survive in the acidic environment for a period upto $4 \mathrm{~h}$ (Figure 1). The general time taken for the process of digestion in the stomach is $3 \mathrm{~h}$ (Hawaz, 2014). Both the isolates satisfy the basic requirement of tolerance of acidic stress. The results of our study are thus at par with earlier reports (Mourad and Eddine, 2006; Hawaz, 2014) and can be suitably tested further for their probiotic characteristics.

\section{Determination of their resistance to bile salt}

Tolerance to bile salts is considered to be another prerequisite for colonization and metabolic activity of bacteria in the small intestine of the host. Therefore, when evaluating the potential of using lactic acid bacteria as effective probiotics it is generally considered necessary to evaluate their ability to resist the effects of bile acids (Mourad and Nour-Eddin, 2006). The concentrations of bile salt used for the testing of the stains in the present study (viz. $0.3 \%$ and $1.5 \%$ ) represents the extreme concentration obtained in human intestine during the first hour of digestion (Gotcheva et al., 2002) after which, the normal level of bile salt in the intestine is around $0.3 \%$. The resistance to bile salts varies from one lactic acid bacterial spp. to another and even between strains themselves. Bile resistance of some strains is related to 
specific enzyme activity-bile salt hydrolase (BSH) which helps hydrolyse conjugated bile, thus reducing its toxic effect. In the present study, though both the isolates tolerated $0.3 \%$ as well as $1.5 \%$ bile salts, the lactobacilli isolated from Idli batter (LAB IB) showed better tolerance to $0.3 \%$ and $1.5 \%$ concentration of bile as compared to lactobacilli isolated from Curd (LAB C) (Figure 2).

\section{Determination of their resistance to antibiotics}

The presence of transmissible antibiotic resistance markers is thus an important safety criterion for the evaluation of strains to be used as probiotics. Bacteria used as starter cultures for the production of foods could possibly contain antibiotic resistance genes. But intrinsic resistance to some antibiotics is inherent to the physiology of certain probiotic strains because of their cell wall structure or other inherent physiological characteristics.

The expression of resistance to an antibiotic is considered a risk factor if strains are suspected of harboring acquired, transferable antibiotic resistance genes, as suggested by expression of resistance to an antibiotic that exceeds the range determined to be normal for the species. In many instances, resistance to antibiotics is not transmissible, and the species also are sensitive to many other clinically used antibiotics. No particular safety concern, therefore, is associated with an intrinsic type of resistance. Therefore, in the current study, on performing antibiotic susceptibility test using Disc Diffusion Method, both LAB C and LAB IB though sensitive to Norfloxacin, showed resistance to all other antibiotics used in the study viz. Nalidixic acid, Nitrofurantoin, Cephalothin, Ampicilin, Co-trimaxazole (Table 1). These results concur with WHO reports which state the resistance of Lactobacillus to various classes of antibiotics such as $\beta$-lactam ring and aminoglycoside group. The lactobacilli strains having resistance to antibiotics might be useful in co-administration with antibiotics in the treatment of intestinal disorders and/or in preventing antibiotic-induced diarrhea, in situation when resistance genes present in the probiotic strains are silent (Hummel et al., 2014). This property of Lactobacillus against some antibiotics would thus, in fact be useful for preventive and therapeutic purpose in controlling intestinal infection.

Fig.1 Graph depicting survival of isolates at $\mathrm{pH} 3$

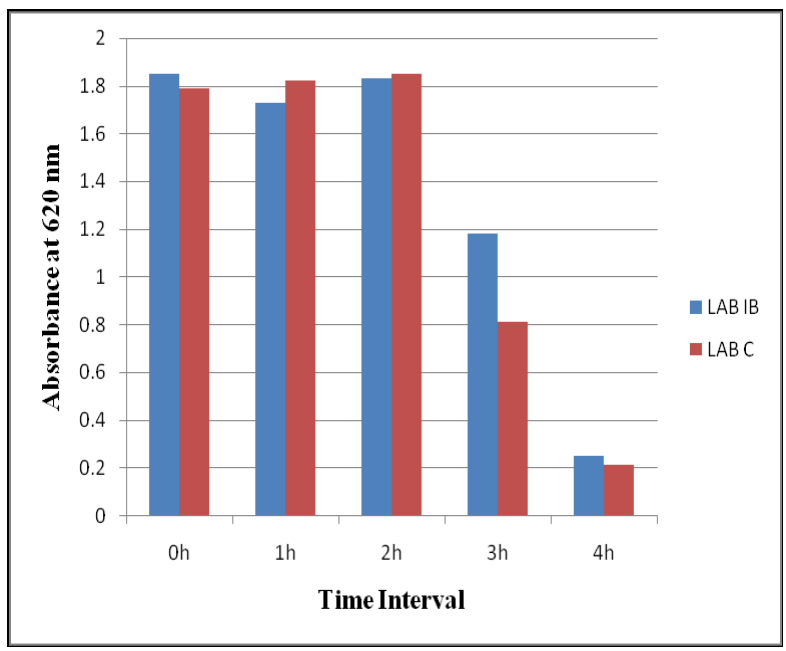


Fig. 2 Graph depicting survival of isolates in presence of $0.3 \%$ and $1.5 \%$ bile salts

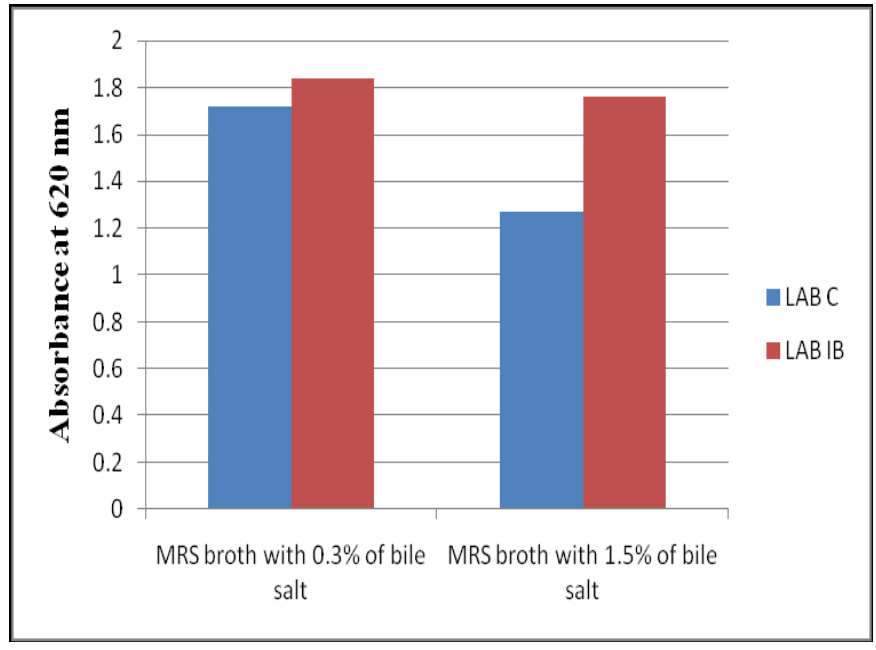

Fig.3 Antimicrobial activity of Lactobacillus isolates

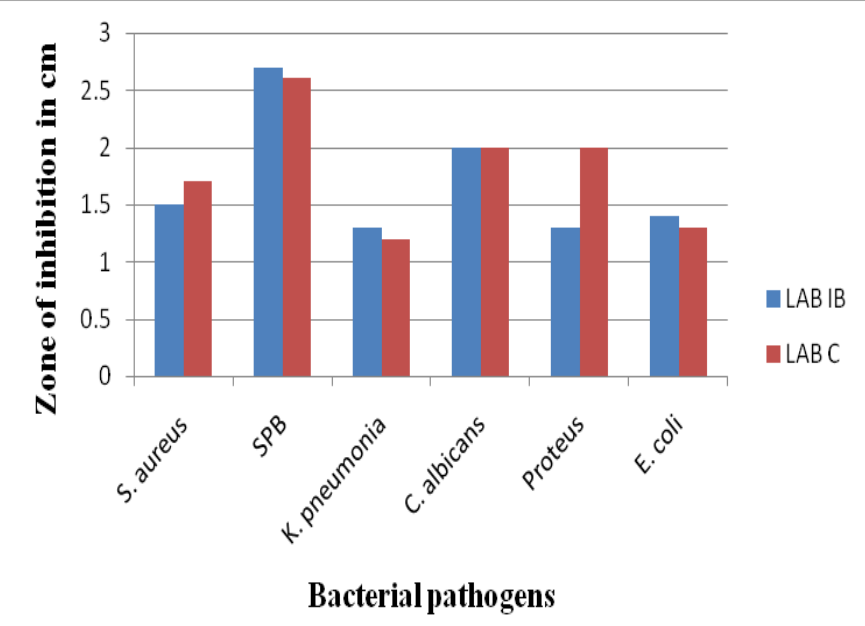

Table.1 Antibiotic sensitivity of the Lactobacillus isolates

\begin{tabular}{|c|c|c|c|c|c|c|}
\hline Isolates & Nalidixic acid & Norfloxacin & Nitrofurantoin & Cephalothin & Ampicilin & Co-trimaxozole \\
\hline LAB C & $\mathrm{R}$ & $\mathrm{S}$ & $\mathrm{R}$ & $\mathrm{R}$ & $\mathrm{R}$ & $\mathrm{R}$ \\
\hline LAB IB & $\mathrm{R}$ & $\mathrm{S}$ & $\mathrm{S}$ & $\mathrm{R}$ & $\mathrm{R}$ & $\mathrm{R}$ \\
\hline
\end{tabular}

KEY: R: RESISTANT; S: SENSITIVE

Furthermore, the chances of transferring low level of resistance (intermediate susceptibility) are limited because such resistance is intrinsic and not plasmid mediated, and thus, the strains are safe to be used as probiotics (Halder and Mandal, 2015).
Determination of their antimicrobial activity on bacterial pathogens

The antimicrobial effect of lactic acid bacteria has been appreciated by man since ancient times and has enabled him to extend the shelf 
life of many foods through fermentation processes. Innovative approaches have been tried as alternative to antibiotics in treating gastrointestinal diseases and these include using live biotherapeutic agents such as probiotic bacterial isolates. Lactic acid bacteria exert strong antagonistic activity against many microorganisms, including food spoilage organisms and pathogens. The benefits derived from a regular intake of probiotic foods are also correlated to their ability to inhibit pathogens and protect humans from gastrointestinal diseases (Lavermicocca et al., 2005).

Lactic acid bacteria produce various compounds such as organic acids, diacetyl, hydrogen peroxide, and bacteriocin or bactericidal proteins during lactic fermentations The bacteriocins from the generally recognized as safe (GRAS) lactic acid bacteria (LAB) are now being used as a novel approach to control pathogens in foodstuffs.

In the present study as well, both the Lactobacillus isolates (LAB C and LAB IB) were found to show antibacterial activity against various pathogens used in the study viz. Escherichia coli, Staphylococcus aureus, Klebsiella pneumoniae, Proteus, Candida albicans, Salmonella paratyphi B. Out of the two isolates of lactobacilli, LAB C was found to be more inhibitory towards Staphylococcus aureus and Proteus while LAB IB was more inhibitory towards Salmonella paratyphi B, Klebsiella pneumoniae and Escherichia coli. Candida albicans however was found to be inhibited to the same extent by both LAB C as well as LAB IB (Fig. 3). Thus, both the isolates showed a broad spectrum activity towards the pathogens used in the study. Based on all these characteristics, both the isolates of lactobacilli were found to be suitable candidates to be used as probiotic strains.
With newer strain-specific clinical trials and meta-analysis of the clinical trials, the beneficial role of probiotics in certain diseases has been evolving. Some uncertainity still exists with probiotics in other diseases with regard to the therapeutic role, strainspecificity, dosage and duration. Identification of clinical characteristics of effective probiotic strains, their mechanisms of action and testing of probiotic-based treatment may provide the true beneficial effect of probiotics in various disorders.

\section{References}

Anja S. Hummel, Christian Hertel, Wilhelm H. Holzapfel, and Charles M. A. P. Franz1 2007. Antibiotic Resistances of Starter and Probiotic Strains of Lactic Acid Bacteria. Applied and Environmental Microbiology, 73, pp: 730-739.

Bathal Vijaya Kumar, Mannepula Sreedharamurthy, Obulam Vijaya Sarathi Reddy, 2015. Probiotication of Mango and Sapota Juices using Lactobacillus Plantarum NCDC LP 20. Nutrafoods, 14 (2), pp: 97-106.

Bauer, A.W., W. M. M. Kirby, J. C. Sherris, and M. Turck 1966. Antibiotic Susceptibility Testing By a Standardized Single Disk Method. American Journal of Clinical Pathology, 45:493-496.

Debashis Halder, Shyamapada Mandal, 2015, Curd Lactobacilli with probiotic potentiality, Translational Biomedicine, 6 (2), pp: 1-6.

Hawaz, E., 2014. Isolation and identification of probiotic lactic acid bacteria from curd and in vitro evaluation of its growth inhibition activities against pathogenic bacteria. African J. Microbiol. Res., 8(13), pp: 1419-1425.

Miriam Bermudez-Brito Julio Plaza-Díaz Sergio Muñoz-Quezada Carolina 
Gómez-Llorente Angel Gil, 2012. Probiotic mechanism of action. Ann Nutr Metab., 61, pp: 160-174.

Mourad, K., and Nour-Eddine, K. 2006. In vitro pre-selection criteria for probiotic lactobacillus plantarum strains of fermented olives origin. Int. $J$. Probiotics Prebiotics. 1, pp: 27-32.

Paola Lavermicocca, Francesca Valerio, Stella Lisa Lonigro, Maria De Angelis, Lorenzo Morelli, Maria Luisa Callegari, Carlo G. Rizzello,and Angelo Visconti 2005. Study of Adhesion and Survival of Lactobacilli and Bifidobacteria on Table Olives with the Aim of Formulating a New Probiotic Food. Appl. Environ. Microbiol, 71(8), pp: 4233-4240.

Sanders, M.E., Gibson, G.R., Gill, H.S. and Guarner, F. 2007. Probiotics: Their Potential to Impact Human
Health. Council for Agricultural Science and Technology Issue paper (36), pp: 1-20.

Setyawardani, T., Rahayu, W.P., Maheswari, R., Palupi, N.H.S. 2011. Identification and Characterization of Probiotic Lactic Acid Bacteria Isolated from Indigenous Goat Milk. Ani. Production, 13(1), pp: 57-63.

Velitchka Gotcheva, Eli Hristozova, Tsonka Hristozova, Mingruo Guo, Zlatka Roshkova (2002), Assessment Of Potential Probiotic Properties Of Lactic Acid Bacteria And Yeast Strains, Food Biotechnology, 16 (3), pp: 211-225.

Vijaya K. Gogineni, Lee E. Morrow and Mark A Malesker 2013. Probiotics: Mechanisms of Action and Clinical Applications, J Prob Health, 1(1), pp: 111.

\section{How to cite this article:}

Shilpa Sabnis and Neha Pawar. 2017. Isolation and Characterization of Probiotic Lactobacillus spp. from Fermented Food Sources. Int.J.Curr.Microbiol.App.Sci. 6(9): 2755-2761. doi: https://doi.org/10.20546/ijcmas.2017.609.340 